\title{
INTIMIDADE EM TEMPO DIGITAIS: O ESQUECIMENTO DA RELAÇÃO FACE A FACE
}

\author{
Intimacy in digital time: forgetting the face-to-face relationship \\ Intimidad en tiempo digital: el olvido de la relación cara a cara
}

RENAN SiLVA CARLETtI GiLBERTO SAFra

\begin{abstract}
Resumo: Este trabalho pretende discutir a noção de intimidade apresentada por Peter Sloterdijk e os efeitos da tecnologia digital na relação interfacial. O objetivo é mostrar como a articulação entre psicanálise e fenomenologia apresentada pelo filósofo alemão contribui para a compreensão de fenômenos clínicos e cotidianos. Por meio de estudos anteriores e situações clínicas mostraremos a substituição da lógica conjuntiva pela conectiva, como apresentada pelo filósofo italiano Franco Berardi, a qual tem gerado vínculos pouco enraizados em vivências corporais. As descrições das experiências temporais e corporais são centrais para compreender esta mudança que está ocorrendo. Neste sentido, concluímos que as facilidades da tecnologia podem se desdobrar em um esquecimento do espaço interfacial como memória e porta de entrada para o mundo.
\end{abstract}

Palavras-chave: Intimidade; Tecnologia digital; Relação face a face; Corpo.

Abstract: This paper intends to discuss the notion of intimacy presented by Peter Sloterdijk and the effects of digital technology on the interfacial relationship. The objective is to show how the articulation between psychoanalysis and phenomenology presented by the German philosopher contributes to understand clinical and everyday phenomena. Through previous studies and clinical situations, we will show how the substitution of the conjunctive logic to a connective one, as presented by the Italian philosopher Franco Berardi, has generated ties that are not deeply rooted in bodily experiences. Descriptions of temporal and bodily experiences are central to understanding this change that is occurring. In this sense, we conclude that the facilities of the technology can generate a forgetfulness of the interfacial space as a memory and a gateway for the world.

Keywords: Intimacy; Digital technology; Face to face relationship; Body.

Resumen: Este artículo tiene como objetivo discutir la noción de intimidad presentada por Peter Sloterdijk y los efectos de la tecnología digital en la relación interfacial. El objetivo es mostrar cómo la articulación entre psicoanálisis y fenomenología presentada por el filósofo alemán contribuye a la comprensión de los fenómenos clínicos y cotidianos. A través de estudios previos y situaciones clínicas, mostraremos la sustitución de la lógica conectiva por la lógica conectiva, tal como la presentó el filósofo italiano Franco Berardi, que ha generado vínculos poco arraigados en las experiencias corporales. Las descripciones de las experiencias temporales y corporales son fundamentales para comprender este cambio que está ocurriendo. En este sentido, concluimos que las instalaciones de la tecnología pueden convertirse en un olvido del espacio interfacial como memoria y puerta de entrada al mundo.

Palabras-clave: Intimidad; Tecnología digital; Relación cara a cara; Cuerpo.

\section{Introdução}

Este trabalho surgiu a partir de reflexões clínica e cotidianas a respeito da presença da tecnologia digital em nossas vidas. O texto parte de conceitos do filósofo Peter Sloterdijk e o dialoga com outros autores como Sherry Turkle, Franco Berardi e Friedrich Kittler. Nossa proposta não se trata de fundamentar um conceito de intimidade em nenhum dos autores anteriores, ou mesmo colocálos em debate, mas aproximá-los como ferramentas de compreensão a partir do encontro clínico. Entendemos que os autores possuem divergências na compreensão das novas tecnologias, no entanto, a proposta deste artigo não trata de colocar em debate estas posições.

Entendemos que a compreensão de intimidade para o filósofo alemão Peter Sloterdijk colabora com esta discussão, pois privilegia a relação e não os sujeitos isolados envolvidos em uma relação íntima. $\mathrm{O}$ foco naquilo que acontece nesse interstício da presença de duas pessoas, esse entre, abre a possibilidade de compreendermos as mudanças ocorridas na experiência corporal com o outro.

Deste modo, há sempre um meio que se coloca no entre do ato comunicativo. Nesta perspectiva, o aparelho celular pode ser compreendido como um mediador da comunicação em que cria novas possibilidades de interação com o outro. No entanto, ele estabelece modos específicos para a comunicação. A textura da tela não pode ser modificada, a ativação de notificações demanda uma atenção específica para o aparelho e reduz a atenção aqueles que estão ao redor (Turkle, 2015).

Além disso, na atualidade, enfrentamos uma certa confusão em relação às diferenças no agir 
comunicativo mediado por diferentes meios. Mandar um áudio por WhatsApp é o mesmo que ouvir a voz de uma pessoa sem mediação do aparelho? Fazer uma ligação telefônica tem diferença para a troca de diversas mensagens de áudio? Qual a diferença entre mandar um email e escrever uma mensagem por Whatsapp?

Todas estas são questões que merecem nossa atenção para que possamos elaborar uma compreensão que não demonize a técnica e a tecnologia na vida contemporânea, mas possa realizar uma aproximação lenta e precisa sobre o que tem se passado em nosso cotidiano. Para este artigo, focaremos a relação face a face e as mudanças que as novas tecnologias tem proporcionado neste campo térmico de animação recíproca (Sloterdijk, 2016).

Para isso, iremos nos partir das discussões da psicóloga americana Sherry Turkle e do filósofo italiano Franco Berardi mostraremos como está em curso uma mutação na sensibilidade mediante a intermediação cada vez mais intensa dos meios digitais. A primeira possuía uma densa carreira acadêmica nos estudos de psicologia e interações com tecnologias digitais. Pioneira na área, Turkle (1995) dedica-se à relação com os aparelhos desde os inícios dos anos 90, trazendo uma abordagem histórica e equilibrada sobre o fenômeno.

Franco Berardi (2017) dedicou um livro chamado Fenomenologia do Fim as mutações na sensibilidade com o advento do que denomina "lógica conectiva" em sobreposição a "lógica conjuntiva”. Em um ensaio fenomenológico, o autor traz minuciosas operações onde os aparelhos digitais modificaram nossa apreensão da realidade e da relação com o corpo. Entendemos que ele fornece um sólido aporte para discutirmos a intimidade no contexto atual. Após a apresentação das considerações teóricas, realizaremos uma discussão com situações clínicas que envolvem a relação face a face.

Turkle (2011) indica que "a tecnologia tem se proposto a moldar nossas intimidades" (p. 1); passando cada vez mais tempo conectados, temos deixado nosso corpo à mercê das telas. Olhares, gestos e convocações perdem-se em meio a intensidade de notificações, postagens, stories entre outros atrativos cheios de cor e fluidez. Com isso, o corpo, aquele que nem sempre é tão fluído quanto os aparelhos tecnológicos, tem sido ignorado enquanto veículo fundamental da comunicação e este esquecimento têm gerado efeitos aos quais iremos apresentar neste trabalho.

\section{Intimidade, uma compreensão a partir do entre}

O termo "intimidade" tem diversas conotações na atualidade. Peter Sloterdijk busca tratá-lo a partir de uma narrativa filosófico-histórica mostrando a importância desta experiência para a constituição humana. Em sua obra Esferas I - Bolhas (Sloterdijk, 2016), considerada uma "arqueologia da intimidade" (Sloterdijk, 2007, p. 113), encontramos pistas, pegadas, marcas, esculturas, pinturas e poemas que nos aproximam deste fenômeno que se inscreve desde os tempos remotos da vida e da espécie humana.

Para ele, o termo carrega a gênese da formação das culturas, a união divina descrita no mito de Adão e Eva, e guarda raízes na relação entre uma mãe e um bebê ${ }^{1}$. Empenhando uma tarefa pelo caminho da fenomenologia, Sloterdijk vale-se de descrições pormenorizadas desta relação para poder explorá-la e dignificá-la de modo que a filosofia, até então, havia ignorado. Astuta, principalmente nas últimas décadas, às experiências de estranhamento, a filosofia pouco se debruçou sobre o aconchego e o calor da presença do outro. $\mathrm{Na}$ contramão deste caminho, Sloterdijk (2016) postula a intimidade, assim como as sociedades, religiões e grupos, como "sistemas imunológicos". Sistemas que nos protegem das contingências de um exterior indiferente às expectativas humanas.

Neste sentido, a intimidade aproxima-se de uma experiência de segurança e conforto para a aquisição de uma confiança que possibilite o estar no mundo. Confiar de modo que seja possível existir sem pressupor que o mundo irá se desfazer ou desabar no instante seguinte. Essa confiança é gerada e experimentada como um continuum desde a experiência intrauterina. Na proteção do espaço uterino como lugar e da placenta enquanto “acompanhante originário” (Sloterdijk, 2016, p. 311) é que ocorre a nutrição da possibilidade de habitar o mundo. Para explorar estes momentos de sustentação, Sloterdijk traz algumas obras artísticas e culturais para o acompanharem em seu percurso, vejamos algumas delas.

Uma primeira descrição se detém sobre o trecho inicial do texto bíblico do Gênesis. Sloterdijk (2016) explicita o sopro como forma de aliança entre criador e criatura. Com isso, o filósofo deseja mostrar o caráter de vasilhame que o humano porta ao se servir de receptáculo para o sopro divino. $\mathrm{O}$ criador só se faz enquanto tal, na medida em que consegue através desta aliança ter uma criatura que o reconheça, ou seja, um veículo de seu ato criador. Assim, a dupla criador-criatura não pode ser pensada separadamente. O que está em jogo nesta relação é menos a consideração isolada em cada um dos polos do que o sopro que os anima de forma conjunta.

A partir disto, Sloterdijk inaugura a possibilidade de pensar a "arquitetura do self" (Safra, 2014) como este espaço ressoante e oco

1 Os termos "mãe" e "bebê" exemplificam uma relação de cuidado e acolhimento de forma rítmica e sintônica. Poderíamos tratar a noção de mãe, próxima à compreensão de "função materna" (Coriat \& Jerusalinsky, 1987); no entanto, o termo "função" não ressoa a perspectiva desenvolvida por Sloterdijk. Ainda assim, podemos sugerir uma "disposição" para uma relação de cuidados iniciais entre uma pessoa e um bebê. 
de um vasilhame que pode acolher um sopro: "a relação entre sujeitos humanos que compartilham um campo de proximidade deve ser descrita como a que existe entre recipientes instáveis que se contêm e se excluem reciprocamente" (Sloterdijk, 2016, p. 78). Percebemos que Sloterdijk está preocupado em descrever o entre que existe na relação e dinâmica que ocorre neste espaço, não explorar como cada um dos polos vive uma determinada experiência.

Tal perspectiva pode ser considerada uma ontologia dual em que é preciso experimentar a relação à "dois" para, posteriormente, perceber-se "um", como descreve Pessanha (2016) ao comentar a perspectiva do filósofo alemão:

A orfandade requer a sustentação, assim como o ser ejetado e jogado no mundo pede um receptáculo imunológico de proteção e hospitalidade. O ser humano precisa ser dois dentro de um receptáculo imunológico para tornar-se um depois. Se ele não participa desse dueto ressonante em um espaço interior, não emerge como um si mesmo. $\mathrm{O}$ espaço interior sustentado é a província onde acontece o belo salto em que crio e sou criado por aquilo que encontro (p. 107).

Pessanha (2016) explicita a necessidade da relação para o ato de emergir para o mundo. O espaço de proteção que a relação possibilita é, justamente, o que irá fazer florescer um sujeito capaz de perceberse como presença no mundo. Dito de outro modo, é a partir de um espaço compartilhado que floresce a percepção de um espaço interior. Há uma co-criação entre os espaços exterior e interior na constituição do humano sustentado por uma dupla que se dispõe ao atravessamento de uma tensão entre proteção e desconhecimento. $\mathrm{O}$ isolamento em um destes polos provoca intensas formas de sofrimento, nas quais a condição de "paradoxo" do existir humano é recusado.

Neste sentido, não é o contato com a própria imagem através do espelho que possibilita uma compreensão da imagem de si. Sloterdijk (2016) argumenta que é tão somente por haver o rosto do outro que podemos nos compreender enquanto nós mesmos. Portanto, não é o espelho que me mostra quem sou, mas o olhar, a voz e o corpo do outro que me abrem a possibilidade de encarar meu corpo enquanto meu (Safra, 2004). Assim, para ocupar um lugar no mundo é, ao mesmo tempo, necessário poder ter sido habitado por alguém. A mutualidade entre corpo e presença ${ }^{2}$ tecem em conjunto a possibilidade da emergência do humano.

Neste jogo de gestos de apropriaçãoincorporação, os períodos iniciais do bebê são vistos

2 Entendemos que a presença se distingue do corpo, na medida em que ela pode se apresentar através do caráter transicional dos objetos e das experiências. Assim, a presença não se resume ao corpo, mas, necessita dele para sua criação. como trocas intensas entre ele e a mãe. Sloterdijk (2016) critica o termo "objeto" utilizado pela psicanálise freudiana para descrever a relação do bebê com o seio, compreendendo que este termo não ressoa a perspectiva relacional e interativa que acontece quando o recém-nascido se alimenta. Esta linguagem estaria ancorada na perspectiva positivista da qual a psicanálise freudiana se alimentou em que a dimensão sujeito-objeto poderia ser transposta para a relação entre o bebê e o seio.

Diferente disto, à Sloterdijk interessa mais a gramática demonológica, em seu sentido grego daimon como ato de possuir-se por algo benigno, do que a objetal. $\mathrm{O}$ ato de mamar passa a ser compreendido como uma possessão por demônios benevolentes, linguagem que se aproxima mais de uma ontologia dual do que expressões de um vocabulário técnico-científico. A constituição de um espaço interior corresponde ao fato de "receber uma alma, [...] cair sob o domínio de uma obsessão benéfica, por meio de um contato espiritual e incorporações produtivas" (Sloterdijk, 2016, p. 88). Este processo constitutivo implica um ir-e-vir constante que se inscreve na dança dos corpos em relação.

Tais espaços íntimos, constituídos a partir de uma relação, são assim sintetizados:

[...] espaços interiores partilhados, cossubjetivos e interinteligentes; [...] espaços, na verdade, que só pode existir na medida em que os indivíduos humanos, pela estreita proximidade que mantêm uns com os outros, mediante incorporações, invasões, imbricações, reflexões e ressonâncias - e também, em termos psicanalíticos, mediante identificações -, criam formas particulares do espaço como continentes autógenos (Sloterdijk, 2016, p. 90)

Percebemos que a intimidade não carrega para Sloterdijk um traço individualista, mas retorna o sujeito para a dimensão relacional que não cansa de se inscrever em seu existir. Assim, inaugura uma gramática própria na tentativa de superar uma perspectiva substancial que narra os sujeitos enquanto ilhas isoladas. Para dizer deste "entre", Sloterdijk propõe termos que evocam ações de troca constantes e que, neste interstício fazem brotar uma possibilidade singular de estar no mundo. Tais "formas particulares" abarcam o existir particular, ou melhor, o ato de realizar trocas e incorporações singulares com o outro.

É neste mesmo caminho, de superar o olhar do "um" e privilegiar o que está em "ato entre dois", que ele irá propor a compreensão da relação facial como "espaço interfacial". Neste ponto, Sloterdijk diferencia-se de Emmanuel Lévinas (citado por Sloterdijk, 2016), o qual trata a temática facial à luz da compreensão judaica que se detém, quase 
exclusivamente, sobre a relação pai-filho, de modo que privilegia uma reflexão substancialista sobre os polos deste par, ou seja, de um sujeito em frente ao outro, e não o que ocorre no espaço entre eles quando se olham. Para ultrapassar esta posição, Sloterdijk propõe uma reflexão sobre a "fusão íntima" (2016, p. 198) proporcionada pelo espaço interfacial.

Para encontrar um vocabulário que possibilite a descrição deste espaço, Sloterdijk (2016) recorre a Marsilio Ficino, comentador italiano da filosofia de Platão durante o Renascimento Italiano, e sua teoria sobre o amor. Para Ficino (citado por Sloterdijk, 2016), a relação entre olhares acontece como um disparo de flechas simultâneas em que ambos os envolvidos são atingidos pela "fascinação intersubjetiva" (p. 198). Com isso, o filósofo alemão quer desconstruir uma perspectiva do amor voltada à sensualidade e poder tratá-lo por um viés "cosmoerotológico" (p.199).

Seguindo nesta proposta de ampliar a amplitude deste fenômeno relacional, Sloterdijk (2016) compreende que o espaço interfacial inserese no processo de hominização: "O motor ou protrator eficiente da gênese facial humana torna-se compreensível quando se constata o caráter de estufa de todas as formas de vida pré-históricas e históricas dos hominídeos; o campo térmico interfacial é aí uma célula decisiva” (p. 153). Assim, o autor assinala que a espécie foi gestada neste calor da protração ${ }^{3}$, ou seja, o advento da face é, simultaneamente, a emergência da possibilidade do existir humano.

Neste sentido, o grande evento somático na formação da espécie humana, foi a experiência facial, ainda mais relevante do que a aquisição do polegar opositor (Sloterdijk, 2016). A face possibilitou a abertura ao próximo, o que gerou a capacidade para colaboração e solidariedade. Tais processos, conformados ao processo de seleção natural, tornaram possíveis a formação de grupos e culturas em que o rosto operou como "um oscilador de luxuriante abertura recíproca” (Sloterdijk, 2006, p. 152). Ele protagonizou os movimentos de repulsa e aproximação durante a história humana.

Considerando a experiência interfacial como um espaço que se produz a partir de um entre, percebemos que a proposta de Sloterdijk ressoa com o que Friedrich Kittler (2009) chamou de uma ontologia dos meios. Kittler explicita como a filosofia grega e ocidental, de forma geral, pautouse continuamente em pensar os entes de forma segregada dando pouca atenção aquilo que ocorria neste espaço entre eles. Ainda que este esteja inclinado a refletir sobre os meios de comunicação, entendemos que Sloterdijk busca o mesmo caminho para descrever os fenômenos íntimos.

Aproximando ambos autores, somos convidados a pensar este espaço interfacial no contexto atual. Tal como Sloterdijk pontuou: "Participar da modernidade

3 "A essa derivação - de motivação tanto biológica quanto cultural - dos rostos humanos a partir das faces animais damos o nome de protração” (Sloterdijk, 2016, p. 150). é pôr em risco os sistemas imunológicos que se desenvolveram ao longo da evolução" (Sloterdijk, 2016, p. 23). Quais são estes riscos que estamos correndo quando falamos de intimidade hoje em dia? Divididos entre telas e olhares, o espaço interfacial e o corpo vêm passando por intensas modificações...

\section{A emergência da lógica conectiva}

Em seu livro "Fenomenologia do Fim", o filósofo italiano Franco Berardi expõe que está em curso uma mutação na forma como apreendemos o mundo. Para ele, na época moderna, a lógica que organizava a experiência era a "conjuntiva", ela se dava através da soma infinita de sensibilidades que se apresentavam de forma rizomática e aleatória (Deleuze \& Guatarri citado por Berardi, 2017). Este modo passou a entrar em declínio e, na atualidade, vivemos a emergência de uma experiência sensorial acelerada, com menor intensidade e diversidade denominada "lógica conectiva" (Berardi, 2017).

$\mathrm{Na}$ lógica conjuntiva, a experiência ocorria como uma grande explosão de sensibilidades abrindo um extenso campo de afetação do corpo com o mundo. As mediações eram múltiplas, de forma que o texto tinha sua materialidade por meio da escrita em um material, a música acontecia na presença dos instrumentos e a imagem era uma construção singular através da pintura. Na conectividade, o corpo passa a ter sua diversidade de apreensão do mundo restringida, sobretudo, pela digitalização do mundo. O termo "digitalização" significa aqui a transformação da imagem, do texto e da voz em dados informatizados (bits) (Kittler, 1999).

A emergência deste reino encantado de dados criou um conto de fadas numérico em que algoritmos serão capazes de escolher e resolver situações por nós. Uma quantificação desmensurada do cotidiano explicita a busca em extinguir qualquer incerteza ou dúvida da experiência mundana. Turkle (2015) alerta que há uma sedução em jogo neste modo simplista de compreender o humano e que, constantemente, recorremos a esta tentativa da redução da complexidade da nossa presença no mundo:

A tradição psicanalítica nos convida a cultivar tanto a capacidade de solidão como a capacidade de auto-reflexão contínua. Há muitas coisas que nos desencorajam. Às vezes é apenas a esperança de uma maneira mais simples de nos entendermos. Seria bom se os problemas pudessem ser curados pela pílula certa ou pelo mantra certo ou pelo ajuste comportamental correto (Turkle, 2015, p. 81, tradução nossa).

Diante desta série de atitudes "corretas", no momento atual, vivemos a busca do algoritmo "correto" para explicar quem somos. Alguns autores discutem o tema dos algoritmos postulando-os como "algo" que sabe mais de mim do que eu mesmo, e, 
portanto, é capaz de dizer quem sou ${ }^{4}$. Entretanto, Sherry Turkle alerta para os riscos desta posição profética que o algoritmo tem tomado. A prática psicanalítica convoca para um cultivo não só da auto-reflexão, mas partindo do lugar paradoxal do humano (Safra, 2014), indica que a apropriação desta condição acontece simultaneamente, no encontro radical com um outro na situação clínica.

Neste sentido, Turkle reconhece que o isolamento e a promessa de dizer aquilo que o humano "é" podem ser contornadas por meio do encontro humano. Esta padronização de dados se utilizada como veículo que nos leva ao encontro com outra pessoa, pode revelar uma outra face de nossa época, considerando que "os aplicativos podem nos dar números, mas somente as pessoas podem transformá-los em narrativas. A tecnologia pode expor um mecanismo; as pessoas devem encontrar o significado" (Turkle, 2015, p. 81, tradução nossa).

Desta forma, Turkle situa a irredutibilidade do encontro humano mesmo diante das tentativas de quantificação e previsibilidade promovida pelos aplicativos. As narrativas e significados são gestados no paradoxo entre ausência e presença, dinâmica esta que os aplicativos são incapazes de promoverem se não houver alguém "do outro lado da tela”. As personagens criadas com inteligência artificial, como Siri ou Assistente Pessoal da Google não possibilitam tal experiência, na medida em que estão sempre disponíveis e, por isso, são incapazes de maturar ${ }^{5}$ significados. A memória da presença é uma oposição à lógica conectiva.

\section{A experiência corpo-temporal na lógica conectiva}

Assim como Turkle (2015), Berardi (2017) destaca que nosso modo de compreender e apreender o mundo sempre foi moldado pela nossa interação com os meios de comunicação. A sensibilidade não acontece de forma aleatória ao que a circunda,

\footnotetext{
$4 \quad$ Ver: $\quad$ https://www.youtube.com/watch?v=hL9uk4hKyg4palestra do historiador Yuval Noah Harari no Fórum Econômico de Davos em 2018 em que ele afirma a possibilidade de um algoritmo prever a orientação sexual de uma pessoa através de medidores bioquímicos.

5 Tal expressão avizinha-se da distinção dos três tempos (vercompreender-concluir) descrita por Lacan (1998) e já utilizada para discussão sobre a experiência temporal no contexto atual (Jerusalinsky, 2017). No entanto, me parece que o termo "maturação" em sua acepção culinária (ação de enzimas em um ambiente que proporciona uma qualidade específica a um alimento) possibilita uma apreensão distinta da experiência temporal, distante da proposta lógico-filosófica descrita por Lacan e oposta ao vocabulário tecno-digital já incorporado ao cotidiano capitalista (ex: "preciso trabalhar isso em mim"; "estou processando o que aconteceu comigo"; "não tive um dia produtivo"; "devemos saber gerenciar nosso tempo”). Trata-se de uma tentativa de ampliar a gramática médico-pediátrica desenvolvida por D. Winnicott, o qual também se vale do termo "maturação" para descrever a experiência neonatal. É a partir da incongruência de se pensar a "maturação" de um "algoritmo" que podemos falar de um tempo distinto, vivido e não técnico-operacional. (Esta associação deve-se à proposta de uma cerimônia do chá realizada ao final de uma disciplina sobre “algoritmos e espaço numérico" na ECA sob coordenação da profa. Daniela Oswald no primeiro semestre de 2018).
}

mas desenvolve-se a partir dos meios oferecidos em determinada época. Contudo, com a advento da transformação da experiência sensorial em dados informatizados: "som e imagem, voz e texto são reduzidos a efeitos de superfície” (Kittler, 1999, p. 2, tradução nossa).

Os sentidos tornam-se neutralizados pela digitalização dos objetos, e mais, das próprias relações entre humanos. Qual a distinção entre uma conversa por vídeo em um aplicativo e um diálogo face a face? A face, na interação por vídeo, perde seu relevo e torna-se superfície plana ${ }^{6}$ como Kittler (1999) descreve acima. O áudio de alguém falando enviando por um aplicativo, pode ser considerado uma voz? O som corre solto no arquivo enviado sem as hesitações de uma voz mediante expressões faciais alheias.

As mudanças descritas por Kittler (1999) e Berardi (2017) operam não apenas na qualidade e intensidade da experiência corporal, mas também no tempo vivido por este corpo. O filósofo italiano denomina de cronopatologias (Berardi, 2017) as modificações que a digitalização do mundo tem operado no modo como experimentamos o "fluir do tempo". Para argumentar sobre tal termo, Berardi vale-se da obra $O$ tempo vivido de Eugène Minkowski (citado por Berardi, 2017) para explorar como a experiência temporal tem sido alterada.

Por meio da influência de Bergson, Minkowski apresenta o tempo não como categoria externa ao humano, mas como tempo vivido. Neste olhar, a percepção do tempo está diretamente ligada ao sofrimento psíquico (Minkowski citado por Berardi, 2017), ou seja, há um ritmo vital que permite a elaboração das experiências vividas. Berardi (2017) compreende que aceleração frenética atual tem alterado este tempo maturacional das experiências.

A expressão "tempo maturacional" não é utilizada pelo filósofo italiano, e nos utilizamos dela para designar um fenômeno ao qual pude compreender a partir de um vídeo que circulava nas redes sociais. No material assistido, dois jovens estão em um carro, um deles dirige o veículo e o outro está sentado ao 6 Discutiremos, em seguida, o efeito disto nas relações interfaciais entre uma mãe e seu filho.

7 Tal expressão avizinha-se da distinção dos três tempos (vercompreender-concluir) descrita por Lacan (1998) e já utilizada para discussão sobre a experiência temporal no contexto atual (Jerusalinsky, 2017). No entanto, me parece que o termo "maturação" em sua acepção culinária (ação de enzimas em um ambiente que proporciona uma qualidade específica a um alimento) possibilita uma apreensão distinta da experiência temporal, distante da proposta lógico-filosófica descrita por Lacan e oposta ao vocabulário tecno-digital já incorporado ao cotidiano capitalista (ex: "preciso trabalhar isso em mim"; "estou processando o que aconteceu comigo"; "não tive um dia produtivo"; "devemos saber gerenciar nosso tempo"). Trata-se de uma tentativa de ampliar a gramática médico-pediátrica desenvolvida por D. Winnicott, o qual também se vale do termo "maturação" para descrever a experiência neonatal. É a partir da incongruência de se pensar a "maturação" de um "algoritmo" que podemos falar de um tempo distinto, vivido e não técnico-operacional. (Esta associação deve-se a proposta de uma cerimônia do chá realizada ao final de uma disciplina sobre “algoritmos e espaço numérico” na ECA sob coordenação da profa. Daniela Oswald no primeiro semestre de 2018). 
seu lado. Cada um filma a si mesmo com seu próprio celular enquanto o carro está em movimento. Após alguns segundos, um motoqueiro passa e rouba o celular do motorista. O vídeo termina. Logo, em seguida, um novo vídeo é feito com ambos perseguindo o motoqueiro, aos xingamentos, a dupla acelera o carro e o passageiro filma freneticamente. Poucos segundos depois, em uma curva, ouve-se um barulho e a tela fica preta. Deduz-se que ambos sofreram um acidente. Um deles pergunta o que aconteceu, se o outro está bem... E o indagado responde: "Tô bem, relaxa que filmei tudo.” Fim do vídeo. (Rio de janeiro motoqueiro rouba celular de carro em movimento meu deus joao eu filmei tudo...., 2020)

O que Berardi (2017) discute sobre o tempo, experiência e elaboração nos parece estar sintetizado neste vídeo e ao que ele se destina. Interessa-nos menos a frase final de um dos envolvidos e mais nas implicações daqueles que viveram tal situação compartilharem o vídeo. Tampouco a veracidade do vídeo é relevante, apesar da dramaticidade da cena, pois compartilhamos inúmeros momentos por vídeo e as implicações disto é que queremos discutir. O compartilhamento revela que a experiência foi transmitida através das redes sociais e isto implica um modo específico de lidar com uma vivência. $\mathrm{O}$ ato de compartilhar torna desnecessária a elaboração da experiência por meio de gestos e palavras, ou seja, dispensa o corpo da elaboração em jogo.

O "encaminhamento" do vídeo possibilita contar uma história sem falar de como ela foi vivida. A história conta a si mesma, o corpo fica privado da ação do "tempo maturacional". Esta expressão tem suas referências na distinção husserliana sobre o tempo: retenção - presentação - protensão (Husserl citado por Tatossian \& Moreira, 2014). Não se trata de uma mera distinção passado - presente - futuro, mas de como uma pessoa vive uma situação e, aos poucos, pode se recolocar diante desta experiência de diversas formas. A presentação designa o momento que ocorre a experiência. Esta gera uma abertura para uma retenção que, com a ação do tempo maturacional, está aberta a distintas destinações (protensão). Desta forma, retenção e protensão estão continuamente vivas e disponíveis para serem modificadas por novas experiências vividas.

No caso do vídeo citado, a imagem congela a ação. A retenção e a protensão tornam-se reféns dela. Não é necessário recontar, revisitar a situação, ela já está ali; pronta para ser reassistida de forma ininterrupta. Mais uma vez, uma vez mais... Não é necessário contar, mas apenas mostrar: "deixa só eu te mostrar esse vídeo aqui”. E novamente, a experiência se esvai e o reino da imagem impera em sua autossufiência. A imagem deixa de ter seu papel como guardiã de memórias para, de forma desenfreada, expandir-se em uma atualização frenética em timelines dispersas.
Neste contexto, o aumento de casos diagnosticados com TDAH (Transtorno de Déficit de Atenção e Hiperatividade) reflete a convergência da velocidade acelerada e a dispersão da atenção da experiência corporal com o mundo. Assim, percebemos que uma patologia que acomete a experiência temporal afeta, necessariamente, a forma como experimentamos a nossa capacidade de doar e receber atenção.

A temática da atenção foi tratada por Jonathan Crary em seus livros Suspensões da Percepção Atenção, Espetáculo e Cultura Moderna (1999) e 24/7 - Capitalismo tardio e os fins do sono (2014). Para ele, o principal bem que está em jogo diante desta nova lógica é a atenção, uma vez que, o que os aplicativos fazem é justamente capturar nosso tempo e experiência mantendo-os sobre controle. Não obstante, o fazem durante todos os dias da semana e em todas horas do dia. Seu maior concorrente passa, então, a ser o sono. A única experiência ainda não colonizada de forma deliberada pela lógica conectiva. O sono é o descanso do corpo. A resistência do corpo as convocações de velocidade, produção e atenção demandadas pelo entorno.

Deste modo, estas alterações temporais têm, simultaneamente, ocorrido em nossa experiência corporal. O corpo tem perdido sua capacidade de reter o que vive. A estimulação e interação constante propostas pelos aparelhos exige que o corpo se mantenha sob constante excitação. Na mesma velocidade que esses estímulos o atingem, também se dissipam. Há um cibertempo (Berardi, 2017) que, constantemente, solicita o corpo para que ele acompanhe suas demandas de informação e velocidade. $\mathrm{O}$ corpo em sua (ainda) finitude tem seus limites borrados, confunde-se diante do tempo demandado e o tempo possível.

\section{0 esquecimento da face ou ainda: há palavra sem olhar?}

Em um encontro de grupo terapêutico, uma mãe relata que estava mexendo no celular quando sua filha veio conversar com ela. A garota de apenas quatro anos começou a falar e a mãe passou a responder sem desviar seu olhar do aparelho. Trocaram três ou quatro frases até que a garota chegou mais perto dela, colocou as duas mãos sobre o rosto dela, uma de cada lado e disse: "olha pra mim".

Ainda na sequência do mesmo grupo, uma outra mãe relata uma cena parecida com um filho com cerca de oito anos. Nessa situação, trata-se de uma mãe que trabalhava por meio de um perfil em rede social, criando vídeos sobre conteúdos didáticos. A conversa se inicia, o filho diz: "olha para mim". Ela responde: "estou te ouvindo, pode falar". Algumas frases são trocadas até que ele afirma: "você não está prestando atenção, você está mexendo no Instagram". 
Para Sloterdijk (2016), o encontro facial entre mãe e filho irradia uma luminosidade mútua que sustenta aquela relação. Esta capacidade de emanação de significado pode ser compreendida pela ausência de representação de rostos em imagens de períodos como o da Idade da Pedra. O rosto do outro fazia parte de um domínio valioso em si mesmo que dispensava a representação.

Posteriormente, houveram séculos de representações faciais em pinturas até o advento da fotografia. Na atualidade, temos a possibilidade de fotografar com os celulares e com isso chegamos a selfie. Entretanto, o foco aqui não se trata desta relação com a própria imagem, mas sim, como nos colocamos na proxêmica social ${ }^{8}$ (Hall, 2005). Vamos nos deter então sobre como o uso do celular mostrase presente nesta relação com a presença física do outro.

As situações clínicas relatadas acima reclamam para si o lugar privilegiado da relação interfacial na proxêmica social. Apesar do sem número de fotos, vídeos, pinturas e desenhos que hoje são possíveis, um rosto ainda clama por outro que possa sustentálo no mundo. Consoante a isso, Turkle (2015) relata que um grupo de adolescentes criou uma "regra de três" para as interações entre eles durante os jantares na casa de amigos. Só é permitido mexer no celular quando ao menos três estiverem sem "olhar para baixo". Tal como as cenas relatadas pelas mães, os adolescentes também percebem que o rosto ainda é necessário na experiência estética com o outro. Notamos que a "irradiação mútua" não se restringe ao contato mãe-bebê, mas perpetua-se pelo decorrer da experiência no mundo com o outro.

Uma paciente de 20 anos relatou diversas experiências em que a mãe se mostrava ambivalente para ela. Esta possuía o costuma de relatar aos demais membros da família o que a filha lhe contava em segredo. A aquisição de um celular com WhatsApp pela mãe revelou-se como um elemento de fragilidade a mais na relação entre elas. Dos poucos momentos que conversavam, a mãe ficava constantemente olhando para a tela do celular sob a alegação de que "estou te ouvindo".

Somos levados a pergunta: pode a palavra hoje sustentar-se sem o olhar? Minha perspectiva é de que estamos sendo levados a retomar o significado da relação interfacial como espaço de valor singular e instransponível. De forma que uma chamada de vídeo simula este espaço, mas não o proporciona com a diversidade de nuances e intensidades quando os corpos estão em um mesmo ambiente físico. Hall (2005) em sua categorização da distância física evidencia que quando estamos em um ambiente, os corpos estão o tempo inteiro em jogo a respeito do que estão dizendo um ao outro ${ }^{9}$.

8 Termo cunhado pelo antropólogo Edward T. Hall para designar a comunicação desenvolvida através da proximidade ou distância entre pessoas em um determinado espaço.

9 As distinções são entre distância íntima, pessoal, social e pública. Os números que classificam cada uma variam de uma
A perda da relação facial tem alcançado proporções tão significativas que alguns poucos dias são suficientes para que os efeitos possam ser percebidos em adolescentes com uso frequente de celular. Turkle (2015) comenta sobre um estudo em que crianças de 12 anos ficaram cerca de cinco dias em um acampamento sem contato com seus celulares. Elas foram submetidas a testes que buscavam identificar a capacidade de reconhecerem expressões faciais em fotografias, filmes e atores. O resultado mostrou que após o período sem o uso do celular, houve um aumento na capacidade de reconhecimento das emoções por expressões faciais (Uhls, Michikyan, Morris et. al. citado por Turkle, 2015).

A autora destaca que uma das grandes diferenças do celular para os computadores é que antes, na década de 90, havia a sensação de "entrar" para jogar em uma máquina. Ou seja, havia o momento em que você se conectava a máquina e ali permanecia ligado à ela. No entanto, o smartphone desmanchou este tipo de conexão. Obviamente que as facilidades foram inúmeras diante desta mudança entretanto, a incapacidade que emergiu de não conseguimos distinguir quando estamos interagindo com a máquina e quando estamos dedicando nossa atenção àqueles que estão ao nosso redor deve ser ressaltada (Turkle, 2015).

A confusão entre a disponibilidade facial e interação com a máquina também pode ser verificada por meio da utilização das chamadas "coleiras infantis”. Sob a alegação de proteção da vida das crianças, pais utilizam em espaços públicos molas elásticas que os unem aos filhos, impedindo que um distanciamento que possibilite algum risco físico. No entanto, como observado cotidianamente, tais coleiras são pretextos para uma entrega ainda mais imersiva aos aparelhos e um esquecimento nítido da disponibilidade corporal-facial na constituição humana.

Este panorama torna-se ainda mais preocupante para a psicóloga e cientista social americana quando vislumbramos a interação entre humano e máquina migrar para a supressão do contato social entre pessoas. A respeito disto, Turkle (2015) atentase especificamente aos aplicativos que oferecem possibilidade de interação direta como a Siri, Assistente do Google, entre outros. Para ela, este é um ponto crucial que marca o distanciamento e o esquecimento da importância da relação interfacial nos dias atuais.

Soma-se a isto a tendência constante à preferência de algumas pessoas a terem conversas sobre temas intensos por meio de aplicativos de mensagens. A autora americana supõe que estamos vivendo uma atrofia da empatia. $\mathrm{O}$ esquecimento da face leva a perda da capacidade de se aproximar dos sentimentos alheios. Deste modo, a experiência do diálogo interfacial torna-se precária gerando cultura para outra. 
variáveis importantes ao processo maturacional às quais a digitação não oferece.

A tensão entre o celular e o rosto alheio tem se mostrado mesmo em situações pouco previsíveis, em que a própria presença do aparelho, mesmo desligado, modifica a qualidade da conversa entre pessoas que estão interagindo (Przybyliski \& Weinstein citado por Turkle, 2015). A autora americana descreve que durante uma conversa com um aparelho sobre a mesa, as pessoas tendem a evitar assuntos que possam levar a exposição pessoal ou a conflito de opiniões. Tal situação indica que a possibilidade de interrupção por uma notificação ou para que alguém digite uma mensagem restringe o envolvimento das pessoas em um diálogo.

Deste modo, o espaço interfacial impõe um ritmo específico. Um ritmo sensível e suscetível a variáveis do ambiente que atuam neste entre que se coloca entre duas pessoas. Retomando o que discutimos no item anterior, compreendemos que o espaço interfacial propõe uma abertura ao tempo maturacional. A disponibilidade da face é uma convocação para uma experiência corpo-temporal ${ }^{10}$. Ela protege o humano da velocidade dos dados e o convida para habitar em companhia.

Portanto, o aparelho celular tem se colocado como um novo objeto no espaço interfacial, o qual interfere diretamente no acontecimento deste fenômeno, levando a um possível esquecimento de sua importância em uma relação íntima. Sendo este espaço um dos responsáveis por gerar e sustentar relações futuras, a interfacialidade é um convite ético à participação da “comunidade humana” (Safra, 2004).

\section{Conclusão}

Considerando a importância singular do espaço interfacial para a constituição humana a partir da perspectiva desenvolvida por Sloterdijk (2016), não se pode ocultar, tampouco esquecer, as alterações ocorridas neste espaço com o advento dos smartphones. A distração e o entretenimento têm nos dispersado da relação com aqueles que nos rodeiam, tornando dispensável aquilo que, na realidade, é estruturante para a experiência de existir enquanto ser aberto ao mundo e ao outro. Aquilo que faz memória da condição humana enquanto tal e que nos destina a habitar o mundo de forma conjunta.

O rosto, enquanto marca da intimidade, sentencia a disponibilidade para o encontro humano. Seu retraimento diante da tela impede a atenção devotada que o olhar do outro reclama. Esta reclamação fica sem lugar quando o fascínio de notificações, jogos e timelines imperam em suas demandas ad infinitum. As tecnologias coexistem com o habitar humano no mundo e exercem um fascínio em maior ou menor grau com suas 10 Recordo-me de situações em que ao andar nas ruas do centro de São Paulo, o olhar dirigido aqueles que estão sentados nas calçadas verte-se, imediatamente, em uma alteração na expressão facial da dupla. O reconhecimento da face do outro gesta uma esperança de reconhecimento. inovações. No entanto, é necessário hesitar diante do brilho para que possamos reconhecer o objeto que está produzindo luz e o que ele está a ofuscar.

Há uma intensa mutação na sensibilidade e na experiência de intimidade que os meios digitais têm provocado. A aceleração convocada por aplicativos e interfaces apressa o cotidiano e nos impede de demorarmos e pararmos em algo. As imagens proliferam-se de forma incontrolável e a experiência temporal busca acompanhar, confusamente, o ritmo convocado por elas, fenômeno que denominamos no decorrer do texto de cibertempo.

Crary (2014) nos alerta que o sono se tornou uma das poucas experiências que permanece à margem deste ritmo frenético, pois possibilita um tempo de não-consumo e não-produção. O sono e o sonho ainda resistem como formas de presença desajustadas na atualidade. Aqui as imagens aparecem em uma outra qualidade, sem o brilho e a nitidez dos aplicativos, mas com a névoa onírica e a sombra da memória. O autor sugere que, talvez, justamente aí onde falta clareza e exatidão, podem haver espaços que ofereçam novas possibilidades para aquilo o que nos circunda. O sono resguarda aquilo que ainda está vivo.

Contudo, compreendemos que o espaço interfacial oferece também uma resistência. $\mathrm{O}$ rosto e a tela são convites distintos para experiências distintas. A relação facial guarda e protege um espaço privilegiado. Ao nos aproximarmos das reflexões de Turkle (2015), a autora traz o alerta e indica que ainda não nos perdemos uns dos outros. A ameaça está aí, é constante, presente e aguda. Contudo, ainda somos capazes de reconhecer quando o espaço interfacial emerge como luminosidade mútua e irradia o clarão da experiência íntima.

O exercício clínico da psicologia traduz, nitidamente, o que significa esta estufa íntima que é o campo térmico interfacial. Reúne um convite à pausa, ao estar junto e o enaltecer da relação interfacial. Na escassez desta, o quanto ainda será possível sustentar o lugar do divã? No declínio do rosto, um espaço que possa recolocá-lo em seu lugar privilegiado, deve repensar seus costumes e hábitos. Pretendemos explorar este tema em trabalhos futuros.

Por último, apesar de termos focados os aspectos nocivos da tecnologia digital neste trabalho, compreendemos que a relação com ela não se resume aos tópicos aqui abordados. Em trabalhos futuros, iremos discutir e descrever as possibilidades de uma intimidade desenvolvida no espaço das redes sociais digitais. Corremos o risco de nos tornar cegos para os sofrimentos que nos circundam, caso nos antecipemos aos fenômenos que surgem diante de nós. As relações construídas online, em muitos casos, aguardam e anseiam pelo encontro facial. A superficialidade aparente não apaga a sede por uma experiência íntima. Em alguns casos, pode ser inclusive a ponte que a possibilita. 
Uma chamada de vídeo ou na troca de curtidas, mensagens, envio de fotos ou vídeos; são aberturas para uma relação íntima com o outro. No entanto, estas mediações levam a uma conformação específica e dinâmicas relacionais singulares, as quais devem ser cuidadosamente compreendidas. Estes modos digitais de aproximação apenas mostram-se possíveis, pois: há memória de um rosto que iluminou outro, antes que a luz de uma tela se fizesse presente.

\section{Refrências}

Berardi, F. (2017). Fenomenologia del fin. (Alejandra López Gabrielidis, Trad.) Buenos Aires: Caja Negra.

Coriat, L. \& Jerusalinsky, A. (1983). Função materna e estimulação

Crary, J. (1999). Suspensions of Perception: Attention, Spectacle and Modern Culture. Massachussets: MIT Press.

Crary, J. (2014). 24/7: Capitalismo tardio e os fins do sono. (Joaquim Toledo Jr., Trad.) São Paulo: Cosac Naify.

Hall, E. (2005). A dimensão oculta. (Waldéa Barcellos, Trad.) São Paulo: Martins Fontes.

Harari, Y. N. (2018) Will the Future Be Human? - Yuval Noah Harari (2020, Junho 5). [Arquivo de vídeo]. Recuperado de: https://www.youtube. $\mathrm{com} /$ watch?v=hL9uk4hKyg4

Jerusalinski, J. (2017). Que rede nos sustenta no balanço da web? - o sujeito na era das relações virtuais. In: Intoxicações eletrônicas: $O$ sujeito na era das relações virtuais. Salvador: Ágalma.

Kittler, F. (1999). Gramophone, film and typewriter. California: Stanford University Press.

Kittler, F. (2009). Towards an Ontology of Media. Theory, Culture \& Society. Vol. 26(2-3): 23-31 DOI: $10.1177 / 0263276409103106$ Los Angeles, London, New Delhi, and Singapore: SAGE. DOI: $10.1177 / 0263276409103106$

Lacan, J. (1998). O tempo lógico e a asserção da certeza antecipada. In: Escritos. (Vera Ribeiro, Trad.) São Paulo: Jorge Zahar Editora.

Pessanha, J. G. (2016), Apresentação heterodoxa de um ponto cego de Heidegger visto por Sloterdijk. In: MORATO, H. T. P. e EVANGELISTA, P. E. R. A. Fenomenologia Existencial \& Prática em Psicologia. Rio de Janeiro: Via Verita. precoce. In: Escritos da Criança. Centro Lydia Coriat, Porto Alegre, n.1, 2. ed, 1987

Rio de janeiro motoqueiro rouba celular de carro em movimento meu deus joao eu filmei tudo.... (2020, Maio 19). [Arquivo de vídeo]. Recuperado de: https://www.youtube.com/watch?v=C4PeqZ840Uk

Safra, G. (2004). Po-ética na clínica contemporânea. Aparecida: Ideias e Letras.

Safra, G. (2014). A face estética do self. Aparecida: Ideias e Letras.

Sloterdijk, P. (2016). Esferas I - Bolhas. (José Oscar de Almeida Marques, Trad.) São Paulo: Estação Liberdade.

Sloterdijk, P. (2007). O Sol e a Morte. (Carlos Correia Monteiro de Oliveira, Trad.) Lisboa: Relógio d’Água.

Tatossian, A. \& Moreira, V. (2014). Clínica do Lebenswelt: psicoterapia e psicopatologia fenomenológica. São Paulo: Escuta.

Turkle, S. (1995). Life on the Internet: Identity in the Age of the Internet. New York: Simon and Schuster.

Turkle, S. (2011). Alone Together: Why We Expect More from Technology and Less from Each Other. New York: Basic Books.

Turkle, S. (2015). Reclaiming Conversation: The Power of Talk in a Digital Age. New York: Penguin Press.

Renan Silva Carletti, (https://orcid.org/0000-00018008-0773) Instituto de Psicologia, Universidade de São Paulo. Email: carletti.rs@gmail.com

Gilberto Safra, ( https://orcid.org/0000-0002-55725071) Instituto de Psicologia, Universidade de São Paulo. 